\title{
MIDAS
}

Museus e estudos interdisciplinares

$4 \mid 2014$

Varia e dossier temático: "Museus, utopia e urbanidade"

\section{La ciudad como museo: Interpretaciones para construir utopía y urbanidad}

The city as a museum: Perspectives to build utopia and urbanity

Roser Calaf y Sué Gutiérrez

\section{(2) OpenEdition}

Journals

Edición electrónica

URL: http://journals.openedition.org/midas/728

DOI: $10.4000 /$ midas. 728

ISSN: 2182-9543

Editor.

Alice Semedo, Paulo Simões Rodrigues, Pedro Casaleiro, Raquel Henriques da Silva, Ana Carvalho

Referencia electrónica

Roser Calaf y Sué Gutiérrez, « La ciudad como museo: Interpretaciones para construir utopía y urbanidad », MIDAS [En línea], 4 | 2014, Puesto en línea el 13 febrero 2015, consultado el 19 abril 2019. URL : http://journals.openedition.org/midas/728 ; DOI : 10.4000/midas.728

Este documento fue generado automáticamente el 19 abril 2019.

\section{cc) (†)}

Midas is licensed under a Creative Commons Attribution-NonCommercial-ShareAlike 3.0 International License 


\title{
La ciudad como museo: Interpretaciones para construir utopía y urbanidad ${ }^{1}$
}

The city as a museum: Perspectives to build utopia and urbanity

\author{
Roser Calaf y Sué Gutiérrez
}

\section{NOTA DEL EDITOR}

Artigo recebido a 31.03.2014

Aprovado para publicação a 15.10.2014

\section{Introducción}

1 Partimos de la premisa de considerar la ciudad contemporánea como una estructura pedagógica estable, continua y consistente en la construcción de ciudadanía y urbanidad, donde la cultura y la educación son los ejes transversales del proyecto político. Utopía, pensaran algunos, otros vemos que algunas ciudades españolas se encaminan a este ideario. Que se manifiesta, como observaremos, en sus intervenciones de regeneración urbanística, que revalorizan la ciudad; en el caso de Barcelona donde el museo está en la calle y los espacios prometen ser un buen recurso educativo. Sus esculturas no sólo consiguen simbolizar espacios, sino también regenerarlos y conectarlos al núcleo urbano, así como potenciar el uso social de los mismos. El ciudadano entiende, comprende y se compromete con su entorno y su patrimonio.

2 En este sentido, como en cualquier otro proceso cognitivo y de aprendizaje relacionado con la intervención socioeducativa se pueden manifestar prácticas de tipo: educación formal, no formal e informal. Y si hablamos de patrimonio cultural, la experiencia urbana 
cotidiana se manifiesta mediante un aprendizaje informal, el transeúnte observa, lee y asimila la información que contiene este patrimonio, opina sobre el mobiliario urbano, y puede optar también por ir a la página web de la ciudad para conocer más aspectos culturales (gastronomía, folclore y festividades). El visitante-ciudadano entra en contacto con el patrimonio teniendo la oportunidad de realizar los itinerarios que le apetezcan para conocer la ciudad; la ciudad está virtualmente en sus manos. A partir de esta experiencia la persona construye su propia interpretación y definición de la ciudad (Lopes 2008; Prats y Santacana, 2009).

El modelo de Bronfenbrenner (1979) es la representación gráfica del discurso que están reflejando las ciudades en la actualidad, apostar por la capacidad formativa de la ciudad. Cuestión que va a depender de los mecanismos de colaboración que mantengan con otros "sistemas" como la escuela, el museo, servicios sociales, salud, asociaciones, empresas, etc... Todos los niveles del modelo ecológico dependen unos de otros, quitando un eslabón, la cadena de desarrollo social y promoción educativa se fractura.

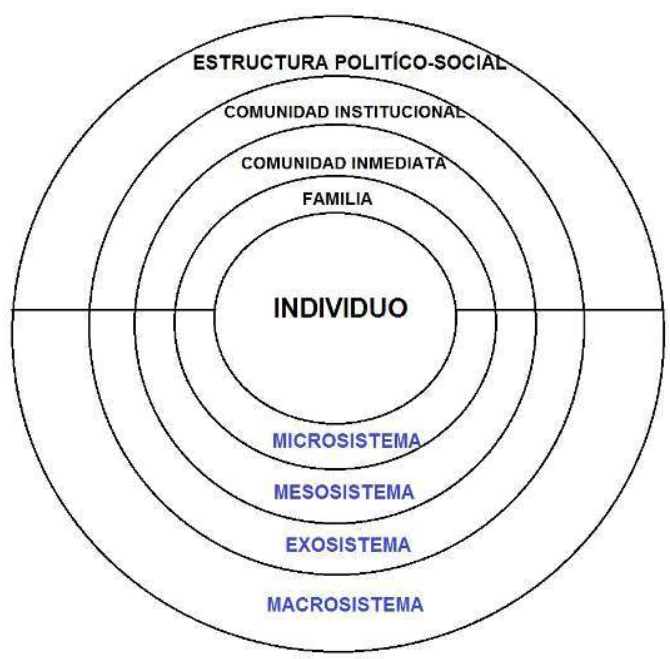

Fig. 1 - Modelo ecológico de desarrollo humano de Bronfenbrenner (1979)

En este sentido, desvelaremos como las disposiciones municipales en materia cultural plantean nuevos escenarios educativos al museo. La ciudad con su patrimonio local (trama urbana, edificios y esculturas) y el museo como mediador, ofrece la oportunidad al ciudadano de valorar, disfrutar, e identificar su patrimonio como propio. Expondremos la experiencia del Museo Casa Natal de Jovellanos de Gijón, una intervención - no formal- de educación patrimonial: enseñanza estructurada, clara y apoyada en experiencias (Fontal 2003).

En ambas intervenciones la ciudad se expresa a sus ciudadanos como un recurso artístico, económico, social y cultural, de carácter dinámico que debe ser eficaz y a la par imprescindible para alcanzar satisfactoriamente el tránsito de la ciudad real a la ciudad ideal (Subirós 1998). Este ideal de ciudad se entiende bajo parámetros urbanísticosociales, encontrando el equilibrio adecuado entre los elementos - capitales - tantos sociales y comunitarios, como económicos y ambientales. El fin último es encontrar la 
sostenibilidad de la ciudad en beneficio del bienestar y calidad de vida de sus ciudadanos (Deakin 2009). Una sociedad de ensueño que valora el hecho de contar historias, de transmitir la cultura, los valores y principios éticos; sociedad del futuro que obliga a las ciudades a realzar su patrimonio cultural (Jensen 2001).

\section{Construyendo utopías y urbanidad en Barcelona}

6 Tomamos como referente la ciudad de Barcelona donde los símbolos que la conforman le dan vida y son susceptibles de ser interpretados por la ciudadanía. (Calaf 2004). Barcelona actuaría como paradigma de ciudad que genera un discurso de modernidad, tradición, transformación y regeneración del espacio urbano. Se trata de una urbe que ha pasado por la revalorización de su suelo mediante la incorporación de obras de arte muy prestigiosas. Así, la escultura pública con Richard Serra, Frank Gehry ${ }^{2}$, arquitecturas de autor como Richard Meier (Museo d'Art Contemporani de Barcelona - MACBA), Arata Isozaki (Palau Sant Jordi), Jean Nouvel (La Torre Agbar), Norman Foster (Torre de Collserola), Beverly Pepper (Cielo Caído en parque de la Estación del Norte) ${ }^{3}$. Intervenciones realizadas bajo la estética del sigo XX y de acuerdo a un plan, el de Oriol Martorell arquitecto que ideó el plan urbanístico ${ }^{4}$ de la ciudad para acoger las Olimpiadas de 1992 con el acuerdo del alcalde Pascual Maragall. Plan basado en los conceptos de: recuperar la fachada marítima, generar plazas y jardines como lugares de encuentro y relacionar el centro con barrios periféricos, incorporando obras muy singulares en ellos que obligan a las personas a visitarlo si desean gozar de las obras de arte de Chillida o Álvaro Siza. Por ejemplo, la obra de Siza ${ }^{5}$, se incorpora a las recientes intervenciones urbanísticas que generan uso de espacios al aire libre para funciones diversas y con equipamientos que generan ciudad educativa, donde ciudad y ciudadano se encuentran, usan y disfrutan.

7 En definitiva, la incorporación de obras singulares junto con este modelo de intervención urbanística de sostenibilidad de los espacios públicos, según Calaf $(2004,116)$ nos permite clasificar estas obras de arte, esculturas, en función de su interacción con el ciudadano en:

8 - Esculturas que simbolizan espacios: Generalmente emplazadas en un espacio de crecimiento de la ciudad, a veces, con nudos de comunicación y la presencia de no lugares y de calles segregadas respecto a la ciudad. Donde las esculturas funcionan como elemento cultural que une o relaciona el barrio con la ciudad. Las piezas escultóricas que pueblan este territorio tienen la función básicamente de integrar paisajísticamente la zona con la ciudad y su entorno que permite una interpretación simbólica de la zona. En este sentido Calaf $(2000,89)$ nos indica varios recorridos por zonas de la ciudad, al relacionar las esculturas, arquitecturas y jardines que manifiestan la relación de objetos artísticos con el lugar.

9 - Esculturas en barrios históricos o en zonas regeneradas urbanísticamente, donde las intervenciones se orientan bajo el argumento de establecer diálogos entre el pasado y el presente.

Tabla 1 - El recorrido por el centro de la ciudad

\begin{tabular}{|l|l|l|l|}
\hline CONCEPTO SUGERIDO & AUTOR & OBRA & AÑO \\
\hline
\end{tabular}




\begin{tabular}{|l|l|l|l|}
\hline Réplica/contrapunto & A. TAPIES & Nube y silla & 1991 \\
\hline Juego/evocación & J. BROSSA & Barcino & 1995 \\
\hline Diálogo en la austeridad & E. CHILLIDA & Topos & 1986 \\
\hline Sorpresa & P. BARRAGAN & Volcán & 1992 \\
\hline Sonrisa & R. LICHTENSTEIN & Cabeza de Barcelona & 1992 \\
\hline
\end{tabular}

El itinerario de Sants y el Parque Joan Miró, que nos señala la misma autora, es un claro ejemplo de procesos de simbolización y reconversión del espacio (Calaf 2000, 95-97). Se reinventa gracias a la reivindicación ciudadana con la voz de "salvemos Sants" y se recupera su memoria industrial y se generan espacios de encuentro, de cultura y de ocio. Tradición y modernidad se estrechan la mano, con la instalación de diferentes esculturas como: el Dragón de A. Nagel (1985) de acero, elemento lúdico que une el interior del parque con el exterior; o la pieza de Anthony Caro, Alto Rhapsody (1985), escultura formada también por acero, pero esta vez oxidado que nos evoca al pasado industrial de la finca. El trayecto finaliza con la yuxtaposición de significados en ambos parques. Así la antítesis agua-tierra del parque de la España Industrial (nombre de la antigua fábrica) y el de sombra y claridad en el Parque Joan Miró (antes estaba el antiguo matadero municipal) con la escultura Dona $i$ ocell de Joan Miró que mantiene fijada su atención para no provocar al Dragón de Nagel.

Para Barcelona, Oriol Bohigas planteó un urbanismo que remitía a la utopía donde pasado y presente se conciliaban, donde las clases sociales se encontrarían para reivindicar un proyecto de ciudad. ${ }^{6}$ Así, el artesanado afincado en barrios tradicionales del casco antiguo se suma a reivindicaciones de los trabajadores industriales de la periferia de la ciudad. El diálogo social estaba instaurado, coincidían en tabernas, plazas, y en ateneos culturales como: "Centre Excursionista", que ha jugado un papel decisivo en este encuentro, ya que también la burguesía amante de la naturaleza frecuenta esta institución. ${ }^{7}$ Todos reivindican mejores condiciones de vida y un proyecto cultural. Esta situación generará la cohesión de intereses y este es el ideario que sustenta la política urbana de la Barcelona del 1992 (Olimpiadas). ${ }^{8}$ Recogemos algunas de las líneas de intervención:

- prioridad a las soluciones de detalle, fijadas en colaboración con criterios elaborados por cada uno de los barrios;

- actuaciones puntuales referidas a dotación de equipamientos y a la reconsideración del espacio público. Ejemplo: regenerar la Plaza Real o aprovechar los huecos del casco antiguo para recuperar espacios de encuentro;

- homogeneización cuantitativa y cualitativa de la ciudad aceptando las bases históricas de la dualidad centro periferia, sus dependencias y diferencias.

En lo argumentado encontramos la idea de ciudad como utopía de urbanidad desde las bases urbanísticas. También, el conjunto escultórico y arquitectónico incorporado a la ciudad confiere a cada espacio un sentido y significado - homogeneizar la ciudad partiendo de las diferencias idiosincráticas de cada barrio - (Calaf 2000, 88). Para cerrar la argumentación sostenida destacamos las palabras de Rubert de Ventós (1998, 63): «organizar la ciudad en términos espaciales - topológicos y no genealógicos - cuestión que responde a un principio democrático propiamente urbano, y no solamente urbano, sino 
precisamente urbano». ${ }^{9}$ La escultura pública crea lugar y crea identidad, y la plaza se convierte en espacio de conversación. ${ }^{10}$ También, permite hablar de la ciudad como un museo abierto (Permanyer y Levick 1991).

\section{La ciudad puede ser. museo, instalación artística y educar desde los espacios urbanos}

13 Observamos que al igual que el museo, cada ciudad dispone de su propia colección y, como sucede en la institución museística, depende de la gestión que se haga de la misma para que el visitante-ciudadano logre experimentar una oportunidad de aprendizaje relevante, sobre lo que fue, es y podrá ser la ciudad, en toda su magnitud, ofreciendo un conocimiento integral de la urbe, de su historia, de sus mecanismos de participación y cohesión social, así como de sus bienes culturales.

Barcelona representa la idea de ciudad como museo "vivo", ciudad como instalación que interactúa gracias a la participación de la ciudadanía, reconociendo lugares significativos, en algunos casos, para sus actos de celebración o reivindicación ${ }^{11}$ y se convierte así la ciudad-patrimonio en un organismo vivo. En un plano menos espectacular se precisa de una acción más específica para potenciar el patrimonio, intervenciones educativas que permitan la construcción de urbanidad y este es el caso de Gijón. La diferencia fundamental entre ambas radica en la claridad y comprensión del mensaje urbanístico. En la ciudad de Barcelona: la intervención responde al contexto donde se ubicaba y a las necesidades de revalorizar las zonas degradadas, sus ciudadanos mostraron comprensión, los identificaron como elementos propios, los integraron en su cotidianidad, y los valoraron como algo que los representa. Una simbología urbana que actúa como proyecto de identificación, donde la ciudad se expresa en su construcción y evolución, siempre asociadas a las decisiones del poder, una transición del periodo franquista a la democracia. Pero al mismo tiempo van unidas estas disposiciones a políticas culturales de activación económica, comercial de ocio y cultura (Calaf 2000).

Sin embargo, en Gijón la historia es bien distinta, en el plano urbanístico hay circunstancias muy cuestionables, existió un proceso de especulación del suelo que la hizo crecer desordenadamente y en vertical. También, la ubicación de edificios, plazas, parques con un marcado signo ideológico preconstitucional: la Universidad Laboral, Parque de Isabel la Católica, Plaza de los Mártires... Este perfil y la filosofía de desprecio respecto a sus bienes patrimoniales se prolongó hasta los primeros años de la década de los noventa del pasado siglo. Con los gobiernos municipales de la Democracia de signo progresista se incorporó un programa de ubicación de escultura contemporánea que trataba de borrar el pasado con nuevos patrimonios. Este mensaje patrimonial no calaba en los ciudadanos, la política urbanística no supo manifestar sus intenciones a la ciudadanía que veía aparecer esculturas e instalaciones que no comprendía. La mofa y el desprecio siguieron como respuesta a la ignorancia de algo que les era ajeno. El ciudadano ni entendía, ni percibía su significación, solo reparaba en el gasto económico que suponían estas piezas para el municipio. Los representantes políticos trataban de salir de la crisis producida por un declive industrial a través de la activación económica por medio de la promoción patrimonial y cultural como recurso turístico. La necesidad informativa de los ciudadanos era imprescindible para conocer qué pasaba en su ciudad respecto al discurso patrimonial, precisaban de entender y comprender su entorno. 

elementos artísticos proyectan un discurso narrativo que permanece silenciado y que es necesario desvelar su significado oculto al transeúnte para que pueda comprender en profundidad la ciudad (Amendola 2000, 38-39). «Saber ver lo que nos hacen mirar, es la tesis central para un programa dedicado a la educación» (Calaf, Navarro y Samaniego $2000,84)$ y para un programa que construya ciudadana.

En consecuencia, las ciudades deben establecer un diálogo con sus ciudadanos y crear las estructuras que las hagan más responsables, abiertas y dinámicas a los continuos cambios de la realidad social. El papel de las instituciones socioculturales es ofrecer acciones formativas significativas que permitan al ciudadano acceder, participar y disfrutar de su entorno. Esta tarea educativa debe perseguir la transformación de la ciudad, entender como los medios de comunicación son productores de la imagen urbana, o estudiar la estrategia de marketing urbano que permita conocer cuál es la imagen ciudad que se proyecta, o bien elaborar una reinterpretación de los tópicos de la ciudad (Subirós 1998; Calaf, Navarro y Samaniego 2000).

El discurso educativo se convierte en un proceso de patrimonilización de la ciudad a través de la simbolización de sus espacios urbanos, estas intervenciones educativas permiten al ciudadano interiorizar, integrar y apropiarse de este patrimonio que forma parte de él y de su memoria. De este modo «se puede entender la ciudad como un espacio para provocar adhesiones relacionadas con los procesos de identificación ideológica en la ciudadanía. Y puede ser un ejercicio adecuado para ilustrar las manifestaciones de la historia fuera del aula» (Calaf 2001, 92).

\section{Una ciudad laboratorio de experimentación entre la regeneración urbana y la construcción de ciudadanía: Gijón}

Es a través de las políticas culturales que la ciudad logra revalorizarse y convertirse en un lugar de calidad, sostenible y cívico. Cada ciudad es un modelo de vida, y Gijón también es un claro ejemplo de ello. En las últimas dos décadas el municipio ha optado por una apuesta firme por la promoción educativa como eje transversal de su desarrollo. ${ }^{12}$ Es ésta su seña de identidad con respecto a otras ciudades asturianas, el tesón por incentivar, promover y desarrollar acciones estratégicas que acerquen la cultura y la educación al conjunto de la ciudadanía. Los inicios fueron duros ${ }^{13}$, pero aún así su mano fue firme para rubricar proyectos de intervención por y para el ciudadano, contamos pues con iniciativas punteras en su momento como: la Universidad Popular, que sigue siendo un proyecto vigente y actualizado, la conversión y creación de la Red Municipal de Bibliotecas, y la Red Municipal de Museos, las más importantes de la región, así como uno de los últimos proyectos, la reconversión de las bibliotecas municipales en Centros Integrados, espacios polivalentes donde se acercan al ciudadano los servicios administrativos municipales, y se pone a su disposición otros como: ludoteca, sala de exposiciones, aulas de cocina, gimnasio, biblioteca y salón de actos. Sin obviar, con todo ello, el apoyo ofrecido a todo tipo de programas de carácter social (problemática de género, drogodependencias, formación para el empleo).

De esta siembra en el tiempo se proyecta el futuro, rompiendo el signo del declive industrial y urbanístico del pasado. Gijón ha seguido un programa parecido al aplicado en 
Barcelona centrado en buscar otro motor para un resurgir que concilie experimentación y construcción ciudadana, coincidiendo en el planteamiento de diferentes estrategias como:

Desarrollo de políticas para la innovación desde los museos y otras instituciones sociales, ejerciendo un importante papel educativo en sus ciudadanos. Esta tarea ha sido muy extensa. Sus programas educativos han enseñando a valorar las propuestas contemporáneas de arte en la ciudad; ${ }^{14}$

Incorporación de simbología urbana, permite hablar de un proyecto de identificación ciudadana con el arte del siglo XX: esculturas, mobiliario urbano;

- Potenciación de la línea de costa como centro de la dinámica ciudadana. Se construyen dos nuevas playas, una junto al barrio obrero al pie del puerto industrial que regenera toda esa zona; y la otra playa es consecuencia de transformar los antiguos astilleros en playa (con su respectivo equipamiento urbano);

- Énfasis en la diversidad y vanguardia cultural: existe diversos eventos destacando uno literario de novela negra llamado Semana Negra, y el Festival de Cine que se remonta a la segunda mitad del siglo pasado Calaf $(2004,122)$.

La ciudad se ha convertido en un proyecto de cultura (Mascarrell 1995). La elaboración del Proyecto Educativo de Ciudad (PEC) es un requisito para ello. Gijón es miembro de la red de Ciudades Educadoras de España desde el año 2003, junto a Barcelona (1990), a Sevilla (1990), a Donostia-San Sebastián (1998), o Zaragoza (2003), entre otras. No cabe duda del compromiso social y educativo adquirido y renovado por el municipio a través de este proyecto donde el ciudadano disfruta y participa de la diversidad y vitalidad cultural de su ciudad.

\section{Algunos ejemplos de los hitos culturales de la ciudad de Gijón}

La estrategia urbanística que planteó Gijón acorde con la imagen democrática del país fue buscar en las esculturas y su emplazamiento la transformación hacia la modernidad democrática que la urbe necesitaba. ${ }^{15}$ La reconceptualización de la ciudad viene marcada por este tránsito del ideario político y por una actuación municipal que persigue que las edificaciones y esculturas hito consigan valorizar, acentuar o apropiar el espacio (Calaf 2001).

Tabla 2 - Esculturas nuevas, espacios nuevos ${ }^{16}$

\begin{tabular}{|c|c|c|c|c|}
\hline \multicolumn{2}{|l|}{ CONCEPTO SUGERIDO } & AUTOR & OBRA & AÑO \\
\hline \multirow{3}{*}{$\begin{array}{l}\text { Regeneración } \\
\text { recalificación } \\
\text { espacios }\end{array}$} & $\begin{array}{l}\text { Suelo militar a uso } \\
\text { ciudadano }\end{array}$ & $\begin{array}{l}\text { EDUARDO } \\
\text { CHILLIDA }\end{array}$ & $\begin{array}{l}\text { Elogio del } \\
\text { Horizonte }\end{array}$ & 1990 \\
\hline & $\begin{array}{l}\text { Antiguo espacio industrial } \\
\text { en barrio obrero y en nueva } \\
\text { playa }\end{array}$ & $\begin{array}{l}\text { MIKEL } \\
\text { NAVARRO }\end{array}$ & Andarín & 1999 \\
\hline & $\begin{array}{l}\text { Potencia línea de costa con } \\
\text { su instalación }\end{array}$ & $\begin{array}{l}\text { FERNANDO } \\
\text { ALBA }\end{array}$ & Sombras de luz & 1998 \\
\hline
\end{tabular}




\begin{tabular}{|l|l|l|l|l|}
\hline \multirow{4}{*}{ Acuerdo social } & Inmigración & RAMÓN & $\begin{array}{l}\text { La madre del } \\
\text { emigrante }\end{array}$ & 1970 \\
\cline { 2 - 6 } & Solidaridad & PEPE NOJA & Solidaridad & 1999 \\
\cline { 2 - 6 } & Equilibrio & $\begin{array}{l}\text { HERMINIO } \\
\text { ÁLVAREZ }\end{array}$ & Sin título & 2001 \\
\hline \multirow{2}{*}{ Evocar el pasado } & Memoria industrial & $\begin{array}{l}\text { FRANCISCO } \\
\text { FRESNO }\end{array}$ & $\begin{array}{l}\text { Torre a la } \\
\text { memoria }\end{array}$ & 2000 \\
\cline { 2 - 6 } & Memoria histórica & JAIME QUESADA & $\begin{array}{l}\text { Monumento a la } \\
\text { República }\end{array}$ & 2000 \\
\hline
\end{tabular}

En el cuadro hemos expresado los conceptos sobre los que se asientan la urbanidad de esta ciudad y la utopía de conciliar pasado-presente con un programa de esculturas que evocan el pasado y que pretenden configurar una lectura de espacio democrático y de acuerdo social.

\section{Museo Casa Natal de Jovellanos Gijón. Un referente en el proyecto de ciudad educadora de Gijón}

El Museo Casa Natal de Jovellanos es uno de los motores culturales del municipio. Desde sus inicios en la década de los 70 del siglo pasado ha perseguido crear una colección potente y mostrar la que ya tiene con el fin de convertir al museo en espacio de ciudadanía. Las corrientes anglosajonas: learning from museums y progressive education (Hein 1998; Hooper-Greenhill 1998; entre otros...) hicieron mella en los promotores y gestores culturales tanto de la ciudad como del propio museo. ${ }^{17}$

No se concibe un museo sin el programa educativo este se ha convertido en un referente para transformar la conciencia ciudadana frente al arte y buscar en el museo un lugar de encuentro (Gutiérrez y Calaf 2013). Se han transformado en espacios públicos, educativos, donde la persona disfruta, vivencia, experimenta y aprende con el patrimonio; se potencia un desarrollo integral y permanente del ciudadano. Esta trascendencia pedagógica debe venir avalada por una acción pedagógica de calidad y coordinada entre todos los responsables sociales y culturales (Calaf 2004; 2009). Este es el eco de lo que vienen anunciando las diferentes corrientes pedagógicas contemporáneas de extender la educación a la vida, a la sociedad, y aprovechar las posibilidades formativas de la comunidad.

El museo como recurso público y educativo está al servicio de la ciudadanía y debe responder a unos propósitos sociales, por este motivo su eficacia y calidad deben estar acreditados. De ahí surge la necesidad de evaluar la intervención socioeducativa que en él se desarrolla, y en concreto la acción que se realiza en el ámbito comunitario aprovechando la ciudad como estrategia educativa. Diseñamos una evaluación pedagógica de la labor educativa, que nos permita conocerla, comprenderla y mejorarla (Tejedor 2000; Escudero 2006; Miguel 1995). Para desarrollar esta labor es necesario el planteamiento de investigaciones cuya metodología sea de naturaleza cualitativa y permita diseñar estándares de calidad, siguiendo la estela del equipo de investigación 
ECPEME (Evaluación Cualitativa de programas Educativos en Museos de España). ${ }^{18}$ Por ello, nos situamos en valorar la eficacia de los educadores del museo en su intervención desde su competencia pedagógica, conociendo además su formación y satisfacción como educadores, así como en analizar su relación laboral con la entidad. Sin olvidar, fijar nuestro interés en conocer el grado de satisfacción del público visitante, bien sean escolares y profesorado acompañante, como público en general.

El tipo de evaluación que se propone consiste en una estrategia de investigación general y curricular, poniendo el énfasis en la observación del contexto de aprendizaje, como de las entrevistas procedentes de los educadores, participantes de las visitas. Se investigan todas las variables que afectan al resultado del programa, seleccionando los aspectos más importantes de su diseño, planificación e implementación, para poder explicar los principios generales subyacentes a la organización y operación del programa. ${ }^{19}$

En el caso que nos ocupa es demostrar como el programa de Reconocer las Esculturas de la Ciudad ha servido para construir un tejido de ciudadanía que acepta y se reconoce con el patrimonio contemporáneo de la ciudad. El valor simbólico se ha manifestado junto con el vínculo del lugar donde se ubican las esculturas (Calaf 2004). Los educadores que "enseñan" este programa de descubrimiento del patrimonio de la ciudad tienen como propósito construir lazos más sólidos entre ciudadanía y el patrimonio.

31 Entre las actividades culturales que integran el programa educativo del museo, el Circuito escultórico del litoral es la que mejor ejemplifica el nexo de unión entre la construcción de ciudadanía y la enseñanza del patrimonio. La actividad se entiende como un continuo diálogo en dos planos simultáneos: por un lado, una conversación entre el educador y los escolares, y a su vez éstos mantienen un discurso con la obra. El primer plano viene guiado por el educador, que prioriza el encuentro íntimo entre la obra y el joven. De esta forma se busca que los jóvenes perciban, sientan y manifiesten sus emociones e inquietudes. Para posteriormente centrarse en algunas indicaciones físicas, descriptivas de la obra, e incluso de la intencionalidad y propósito del autor.

El recorrido escultórico por el litoral introduce temas de índole reflexivo: se hace comparativa sobre el arte tradicional y el moderno; se hacen explicaciones sobre las sociedades modernas y postmodernas donde el motivo artístico varía hacia la abstracción, o como los materiales son significativos en el diseño. Hay un feedback continuo entre educadores y escolares que va enriqueciendo el mensaje expositivo del itinerario, «ejemplificando con objetos, hechos cotidianos del entorno más cercano y propio de los jóvenes, la propia ciudad en la que viven, de la que muchos desconocen los significados y símbolos que la rodean». ${ }^{20}$ Otra de las cuestiones que entran en este juego discursivo es la cuestión de la iconografía y simbología escultórica o arquitectónica de la ciudad y si esta puede convertirse en emblema distintivo de la misma. En este sentido se comenta como en el caso de Gijón fueron muy debatidas y controvertidas las obras de Muriedas con La Madre del Emigrante, y el Elogio del Horizonte de Chillida que supusieron un punto de inflexión en la comprensión artística de partida y la posterior apropiación ciudadana, hasta convertirse la última en el icono de la ciudad. 


\section{Esculturas interpretadas educativamente y revalorizadas}

El itinerario escultórico del programa del Museo Casa Natal de Jovellanos se compone de las obras que en el último lustro han revalorizado la imagen de la ciudad, a pesar de las controversias que suscitaron la instalación y simbología de algunas de las esculturas.

Tabla 3 - Conjunto artístico del recorrido educativo del museo por el litoral

\begin{tabular}{|l|l|c|}
\hline AUTOR & OBRA & AÑO \\
\hline FERNANDO ALBA & Sombras de Luz & 1998 \\
\hline RAMÓN MURIEDAS & La madre del emigrante & 1970 \\
\hline HERMINIO ÁLVAREZ & Sin título & 2001 \\
\hline PEPE NOJA & Solidaridad & 1999 \\
\hline ADOLFO MANZANO & Cantu a los díes fuxíos & 2001 \\
\hline
\end{tabular}

El itinerario lo inicia Sombras de Luz (1998) de Fernando Alba donde se ofrece una explicación de la composición artística y cómo cada plancha está orientada hacia los cuatro punto cardinales, y aunque la escultura está fija se mantiene en continuo cambio debido al juego de luz que proyectan los recortes de las planchas en el suelo. La teoría dice que en los solsticios coinciden las sombras de los recortes circulares de las planchas con los situados en el suelo. Indicando la idea expuesta por el autor dedicar esta escultura a todas aquellas civilizaciones que adoraban al sol y proyectar a la vez al pasado industrial, (la importancias de las acererías, en Asturias) por el uso del acero cortén en la ejecución de la obra. 


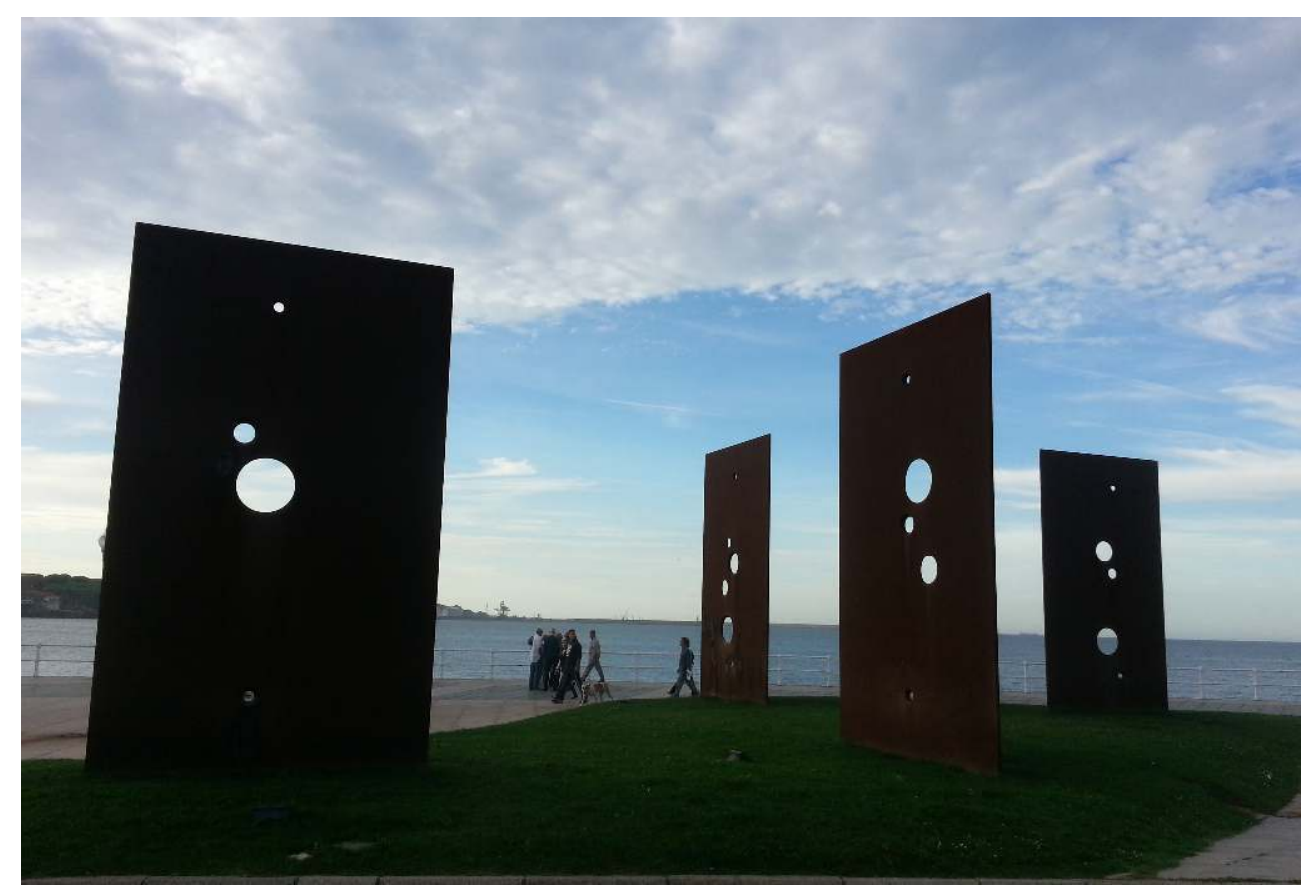

Fig. 2 - Sombras de Luz, Fernando Alba, 1998, Acero Corten, 5 m alto x 5 cm. Ancho (Gijón) (c) Sué Gutiérrez

La Madre del Emigrante, realizada por Ramón Muriedas (1970), ofrece la excusa perfecta para trasladar a los jóvenes la España de principios de siglo XX donde muchos asturianos emigraban, y era un episodio cercano a la ciudadanía. El destino de la obra fue tortuoso, desprestigiada desde el momento de su instalación, dinamitada al poco de su inauguración, y olvidada en los almacenes municipales hasta la época de la transición. La obra no fue entendida por el público quien ha venido descalificando la obra bautizándola con multitud de apodos peyorativos desde: la bruxa, la lloca del rinconín, etc. Con el paso del tiempo la obra cobró sentido para la ciudadanía, entendiendo su mensaje en toda su magnitud, y pasó a convertirse en un hito escultórico contemporáneo de la ciudad. Llama la atención que a pesar de que la emigración era un hecho conocido por todos, el público no supo entender lo que quiso representar el artista con el gesto desgarrado, la desproporcionalidad de las facciones del rostro de esa madre que despide a su hijo, al cual probablemente no vuelva a ver. El artista quiso plasmar como la emigración por aquel entonces era un episodio de perdida, casi comparable a la muerte.

Por último, exponemos la escultura de Adolfo Manzano Cantu a los Díes Fuxíos (2001). La intención del autor ha sido el transformar un no-lugar, en lugar de paso, habilitarlo y convertirlo en un mirador desde el que se ve el Cabo Peñas, Luanco, y la costa de San Lorenzo. Se comenta en la visita que el artista está algo obsesionado con la fugacidad del tiempo, y por ello quiere que el espectador se tome un tiempo en su obra, se relaje y reflexione sobre esos días huidos, pasados. La obra se compone de nueve bloques de mármol que forman el mirador y que ofrecen una evocación a tiempos pasados en los que se celebraba el viaje hacia el más allá. Intervención sutil por el tamaño de las piezas y el material (mármol blanco), las piezas se relacionan en un argumento que hay que descubrir. 


\section{Conclusiones} observaba a la ciudadanía de forma espontánea, sus interacciones con las esculturas, y un sólido trabajo de investigación en los archivos, referenciado en las citas nombradas (Calaf y Fontal 2002). Y en el caso de Gijón, aprovechar la coyuntura del estudio actual en el Museo Casa Natal de Jovellanos, como proyecto piloto de ECPEME, para detenernos en mostrar la "ciudad de las esculturas"22 y como ha conseguido mostrarlas, creando consciencia e identidad ciudadana. Los escolares, que a lo largo de estos años, han visitado estas esculturas de la mano de los educadores del Museo han enseñado a sus padres a apreciar estas obras y con ello ver la ciudad con otros ojos, han conseguido que hoy los ciudadanos de Gijón se sientan orgullosos de sus esculturas. Así muchos de los "recién casados" posan ante la escultura Sombras de Luz, rechazada anteriormente y denostada como el nombre de los "Ementales". La ciudadanía quería ver el mar no la instalación. No entendían que las esculturas potencian la línea de costa y se regeneraba la ciudad con su ubicación estratégica.

Nos gusta cerrar este trabajo con la valoración que realiza Antonio Brusa de la obra Elogio al Horizonte de Eduardo Chillida, y que nos remite a la mayoría de los argumentos que sustentan la utopía y la urbanidad:

El "elogio", en efecto, es un acto político. Expresa la elección de una comunidad que, consciente de los cambios de los tiempos, busca un nuevo camino. Para una mirada superficial eso le aparece como una antítesis estridente con la tradición, la identidad y las raíces de la ciudad. En lo concreto, sin embargo ilustra a los ciudadanos que estas cambian y que una buena democracia sabe reelaborarlos con raciocinio. Hoy la ciudad es consciente de que el "Elogio" es parte integrante del patrimonio de Asturias, así como las valiosas iglesias prerrománicas que atraen a turistas de todo el mundo. Así como su horizonte y su paisaje. (Brusa 2011, 81) 


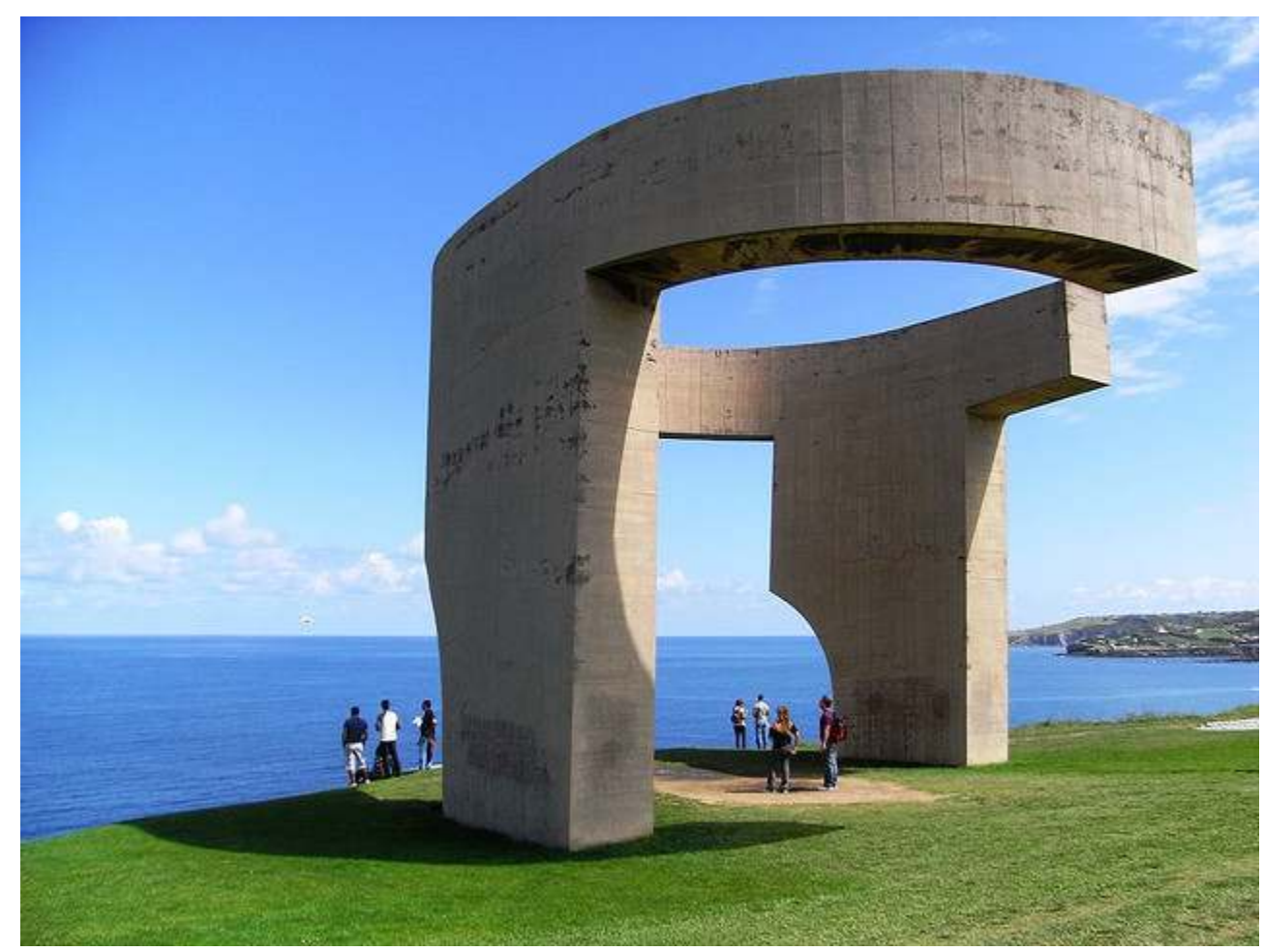

Fig. 3 - Elogio del Horizonte (1990) de Eduardo Chillida. Actual emblema de la ciudad de Gijón, 2008 (C) JAVIER LASTRAS

\section{BIBLIOGRAFÍA}

Amendola, Giandoménico. 2000. La Ciudad Postmoderna: Magia y Miedo de la Metrópolis Contemporánea. Madrid: Celeste Ediciones.

Arendt, Hannah. 1993. La Condición Humana. Barcelona: Ediciones Paidós.

Bohigas, Oriol, Carmina Borbonet i Sant, Juli Capella, y Anna Butí. 1999. Oriol Bohigas: Passió Per la Ciutat: [Exposició Celebrada al Palau de la Virreina, Barcelona, del 21 de desembre de 1999 al 19 de març del 2000]. Barcelona: Electa.

Bronfenbrenner, Urie. 1979. The Ecology of Human Development: Experiments by Nature and Design. Cambridge: Harvard University Press.

Brusa, Antonio. 2011. “Paisaje y Patrimonio, Entre Búsqueda, Formación y Ciudadanía.” Her \& Mus: Heritage \& Museography 3 (2): 80-84.

Calaf, Roser, y Olaia Frontal. 2002. “Esculturas en la Ciudad. ¿Añadir Patrimonio o Borrarlo?” Ciudad y Patrimonio: Revista de Arqueología. Arte y Urbanismo 6: 175-184.

Calaf, Roser, Alfredo Navarro, y José Antonio Samaniego. 2000. Ver y Comprender el Arte del Siglo XX . Madrid: Editorial Síntesis. 
Calaf, Roser, y Olaia Fontal. 2004. Comunicación Educativa del Patrimonio: Referentes, Modelos y Ejemplos. Gijón: Ediciones Trea.

Calaf, Roser. 1993. “Excusionisme i Geografía a l' Escola Obligatoria." En Aportaciones en Homenaje al Profesor Luís Miguel Albentosa, 413-419. Tarragona: Diputación de Tarragona.

Calaf, Roser. 1999. Ciudad como Instalación: Interacciones con Esculturas de Barcelona. Oviedo: Servicio Audiovisual Universidad de Oviedo. Vídeo.

Calaf, Roser. 2000. “Entender la Ciudad como Instalación: la Ciudad de Barcelona.” Iber: Didáctica de las Ciencias Sociales, Geografía e Historia ("La Iconografía en la Enseñanza de la Historia") 26: 85-102.

Calaf, Roser. 2001. “La Ciudad Contemporánea Como Texto: el Caso de Gijón.” Aula: Historia Social 7: 92-101.

Calaf, Roser. 2004. "Aprender Arte en la Ciudad: Sensibilizar Hacia el Respeto y Valoración del Patrimonio Urbano." En Arte Para Todos: Miradas Para Enseñar y Aprender el Patrimonio, coordenado por Roser Calaf, 103-135. Cenero: Ediciones Trea.

Calaf, Roser. 2009. Didáctica del Patrimonio: Epistemología, Metodología y Estudio de Casos. Gijón: Ediciones Trea.

Deakin, Mark. 2009. “A Community-Based Approach to Sustainable Urban Regeneration.” Journal of Urban Technology (16) 1: 91-112.

Escudero, Tomás. 2006. “Evaluación y Mejora de la Calidad Docente.” En Investigación en Innovación Educativa: Algunos Ámbitos Relevantes, coordenado por Tomás Escudero, y A. Delia Correa, 269-317. Madrid: La Muralla.

Fontal, Olaia. 2003. La Educación Patrimonial: Teoría y Práctica en el Aula, el Museo e Internet. Gijón: Ediciones Trea.

Gutiérrez, Sué, y Roser Calaf. 2013. “La Evaluación Pedagógica: una Realidad en el Museo.” Pulso: Revista de Educación 36: 37-53. http://dialnet.unirioja.es/servlet/articulo?codigo=4480301.

Hein, George. 1998. Learning in the Museum. London: Routledge.

Hooper-Greenhill, Eilean. 1998. Los Museos y Sus Visitantes. Gijón: Ediciones Trea.

Jensen, Rolf. 2001. The Dream Society: How the Coming Shift from Information to Imagination Will Transform Your Business. New York: McGraw Hill.

Jiménez, Julián, coord. 2003. La Educación en Gijón 25 años de Escuela Pública, Democrática: Pasado, Presente y Futuro. Gijón: Concejalía de Educación, Ayuntamiento de Gijón.

Lopes, João Teixeira. 2008. “Andante, Andante: Tempo para Andar e Descobrir o Espaço Público.” En Cultura e Vida Urbana: Ensaios sobre Cidade, organizado por Rogério Proença Leite, 129-144. São Cristóvão: Editora da Universidade Federal de Sergipe.

Mascarell, Ferran, dir. 1995. Memòria de Constitució de l'Institut de Cultura de Barcelona. Barcelona: Ajuntament de Barcelona.

Miguel, Mario de. 1995. "La Calidad de la Educación y las Variables de Proceso y de Producto." Ikastaria: Cuadernos de Educación 8: 29-52. http://www.euskomedia.org/PDFAnlt/ ikas/08/08029051.pdf.

Pardo, Josefina, Sué Gutiérrez, y Roser Calaf. 2013. "Museo C.N. Jovellanos: Evaluación de la Acción Educativa del Museo Piloto del Proyecto ECPEME." Comunicación presentada en la 23. ${ }^{\underline{a}}$ 
General Conference of the International Council of Museums (ICOM) CECA.2013 Annual Conference: Museums (Memory+ Creativity= Social Change).

Permanyer, Lluís, y Melba Levick. 1991. Barcelona un Museo de Esculturas al Aire Libre. Barcelona: Ediciones Polígrafa.

Prats, Joaquín, y Joan Santacana. 2009. "La Ciudad un Espacio para Aprender." Aula de Innovación Educativa 182: 47-51.

Ramírez, Juan Antonio. 1991. Edificios y Sueños: Estudios sobre Arquitectura y Utopía. Madrid: Editorial Nerea.

Rogers, Richard. 2008. Cities for a Small Planet. Boulder: Basic Books.

Rubert de Ventós, Xavier. 1998. “Urbanització Contra la Urbanitat.” En Ciutat Real, Ciutat Ideal: Significat i Funció a l'espai Urbà Modern, editado por Pep Subirós, 59-69. Barcelona: Centre de Cultura Contemporània de Barcelona.

Solá-Morales, Ignasi, ed. 1997. Guía de Arquitectura en España. Tanais: Madrid.

Subirós, Pep, ed. 1998. Ciutat Real, Ciutat Ideal: Significat i Funció a l'espai Urbà Modern. Barcelona: Centre de Cultura Contemporània de Barcelona.

Tejedor, Francisco Javier. 2000. “El Diseño y los Diseños en Evaluación de Programas.” Revista de Investigación Educativa 18 (2): 319-340. http://revistas.um.es/rie/article/view/121021/113711.

\section{NOTAS}

1. Esta experimentación se realiza desde el propio planteamiento urbanístico y la proyección educativa que se realiza desde el Museo Casa Natal de Jovellanos, promotor de muchas de las iniciativas culturales que han configurado el proyecto educativo de ciudad educadora. Es el museo piloto del proyecto ECPEME y es, también, objeto de estudio de la tesis doctoral de Sué Gutiérrez titulada: Valoración Didáctica de los Programas Educativos de los Museos de Patrimonio Artístico de Gijón financiada por beca predoctoral Severo Ochoa de Asturias. El Proyecto I+D ECPEME (Evaluación Cualitativa de programas Educativos en Museos de España) pretende establecer un modelo de buenas prácticas en los museos.

2. Richard Serra, El Mur en Plaza de la Palmera, regenerando un barrio obrero y jugando con la metáfora de marca límite a aridez y vegetación; Frank Gehry El Pez en la Villa Olímpica que genera sombra en la línea de playa.

3. Escogemos este ejemplo para argumentar un nivel de intervención en la antigua Estación del Norte de Beverly Pepper Cielo Caído, que regenera un lugar degradado, circundante a la estación del ferrocarril que ha perdido su función (ahora estación de autobús) y lo convierte en un parque lleno de referencias culturales, la obra "dialoga con la obra de Gaudí uso del "trencadis" (cerámica rota) y la espiral construida con la plantación de árboles generando sombra necesaria en zona Mediterránea.

4. Se crea la Villa Olímpica y la correspondiente intervención de soterrar las vías de comunicación de Sur a Norte que cruzaban la ciudad por la costa (ferrocarril, viarios de ronda). Y además se hace necesario crear lugares de encuentro que permitan esponjar la densidad urbana del centro de la ciudad - el Ensanche y del Casco Antiguo.

5. Entre 2004 a 2006, Álvaro Siza hace el "Parc Esportiu de Cornellá" que consiste en una plaza elevada de acceso al complejo deportivo de unos $40000 \mathrm{~m}^{2}$. La silueta ondulante de la piscina permite usos diversos de ocio y de entrenamiento. Su acceso a una zona ajardinada de baños al aire libre, es sin duda un éxito para asentar el concepto de ciudad más equitativa. 
6. Post Mayo del 68 en París, se produce nueva concepción ideológica; una parte de la pequeña burguesía catalana coincide con los intereses de cambio social que también suscriben menestrals (artesanado) y el proletariado surgido en la industrialización. Una concepción de hacer una ciudad democrática se instaura.

7. El papel de esta institución se ha destacado en Calaf (2003).

8. Las ideas centrales están muy bien resumidas en Bohigas et al. (1999).

9. Traducción adaptada al castellano por las autoras de lo texto de Rubert de Ventós (1998).

10. Solá-Morales habla de Oriol Bohigas como pedagogo porque siempre propuso el debate cultural y político en sus clases y en foros en los que participaba (Bohigas et al. 1999, 50).

11. En Barcelona el pasado 11 de Septiembre de 2014 se interviene en dos calles muy significativas de la trama urbana. Elegidas por su nombre, por su conexión con el pasado de la Historia de Catalunya y dimensiones (más de $22 \mathrm{~km}$ una de ellas). El volumen de ciudadanos uniformados con camisetas amarillas y rojas configuraron la gran bandera catalana que debe interpretarse como un acto reivindicativo y una "gran performance". Véase la noticia del periódico El País (11 Septiembre 2014), en el siguiente enlace: http://elpais.com/tag/diada/a/.

12. Esta tradición, más de 25 años dedicados a impulsar la educación en el municipio gijonés, se recoge en el monográfico de Jiménez (2003).

13. En la década de los 80 la ciudad comienza a sufrir una pérdida de identidad, su principal activo de ingresos era el sector industrial que se encontraba inmerso en una profunda crisis que le obligaba a replantearse una transformación. En ese momento se decide apostar por una reconversión del plan de urbanismo impulsado desde un planteamiento de revalorización patrimonial y distinción cultural. Donde se apuesta en primer lugar por la creación del museo como principal activo de desarrollo cultural de la ciudad, desde ese instante se fraguan cuatro de los proyectos museográficos municipales.

14. Desde la iniciativa de la Fundación Municipal de Cultura de Gijón y Universidad Popular del Ayto. de Gijón (1982), se desarrollan los primeros proyectos culturales y se consolida en la década de los 90 cuando la fundación se diversifica en diferentes departamentos (de museos, de bibliotecas y de promoción artística), y se organiza la Red de Museos Municipales. Todo ello unido además al arraigo que tiene la Universidad Popular en la ciudad, creada en 1901, acostumbrada a hacer cultura para el ciudadano. En 1993 se fusiona con la fundación para evitar su desaparición por motivos económicos.

15. Asentada en ideas al planteamiento de Barcelona y en autores como Amendola (2000) y Ramírez (1991).

16. Es el título de la obra editada por el Ayuntamiento de Gijón para conmemorar una década dedicada a regenerar espacios públicos a través de la escultura. Se combina texto e imágenes para mostrar 15 de las obras incorporadas en la ciudad desde 1990.

17. La prueba de ello es la programación educativa del Museo Casa Natal de Jovellanos, título del programa actual: El Museo Constelado. Se utiliza esta metáfora como argumento para mantener un relato conjunto entre las actividades planteadas interpretadas como constelaciones y su relación con la ciudad, como astro rey. Idea presente en los itinerarios urbanos (Acción 1); el museo espacio para la activación de los procesos creativos (Acción 2); museo colabora con el aprendizaje de la historia y la cultura tradicional (Acción 3), y museo y bibliotecas en colaboración para la difusión cultural (Acción 4). Veáse Pardo, Gutiérrez y Calaf (2013).

18. Proyecto I+D ECPEME (Evaluación Cualitativa de programas Educativos en Museos de España) Investigación multidisciplinar e interuniversitaria que vincula profesionales de diferentes áreas y de diversas Universidades españolas (Oviedo, Autónoma de Madrid, País Vasco, Huelva y Zaragoza) y que pretende establecer un modelo de buenas prácticas en los museos. Su I. P es Roser Calaf y Código MICINN-11-EDU2011-27835. 
19. Este es el planteamiento metodológico del proyecto de investigación de la tesis doctoral, que está en curso, de Sué Gutiérrez titulada: Valoración Didáctica de los Programas Educativos de los Museos de Patrimonio Artístico de Gijón.

20. Extraído del cuaderno de campo para la tesis doctoral Sué Gutiérrez Berciano: Valoración Didáctica de los Programas Educativos de los Museos de Patrimonio Artístico de Gijón, que viene desarrollando desde el año 2012.

21. Surge como un movimiento ciudadano de protesta político-social manifestado el 15 de Marzo de 2011 como respuesta a la situación de crisis económica y perdida de derechos en materia laboral y social que consumía a España. Estos ciudadanos manifestaban su malestar reunidos y acampados en la puerta del sol por más de dos meses. Gracias a la difusión en las redes sociales y más tarde los medios de comunicación, el efecto $15 \mathrm{M}$ fue invadiendo el resto de ciudades españolas. El resultado, los españoles tomaron conciencia de su realidad política y social y desde estos grupos de indignados se sigue luchando por que el cambio se produzca. Veáse el origen y desarrollo del movimiento en webs "oficiales" como: http://wiki.15m.cc/wiki/Portada y http:// movimientoindignadosspanishrevolution.wordpress.com/paginas-web-oficiales-del-15m-enespana/.

22. Sué Gutierrez está realizando un estudio en profundidad de los programas educativos en dicho museo en su tesis doctoral. Ver el tríptico que el Ayuntamiento de Gijón facilita en las oficinas de información turística y a través de su website: www.gijon.info/.

\section{RESÚMENES}

Presentamos dos ciudades, Barcelona y Gijón (España), que ejemplifican el desarrollo de la idea de ciudad museo, ciudad instalación, y ciudad potencialmente educativa desde las bases de entender la ciudad como una construcción de urbanidad. Ambas son "ciudad educadora" y patrimonialmente han generado intervenciones en espacios industriales en desuso o incorporando obras de arte, escultura pública, edificios singulares o mueble urbano de diseño, como intervención singular para transformar lugares públicos, con marcado uso cultural y social. En Barcelona se ha desarrollado un proceso de educación patrimonial de naturaleza - educación informal -, la simbología y el valor de las creaciones artísticas han sido entendidas como un hito más de la modernidad e identidad cosmopolita de la ciudad. En Gijón, se ha precisado de un intervención más directa, y propia de la educación - no formal - desde el museo se ha hecho educación patrimonial con los ciudadanos, “enseñándoles a ver" la riqueza histórica y artística de sus calles. En ambos casos se ha creado una simbología urbana que actúa como proyecto de identificación que transmite urbanidad e identidad cultural.

Two cities, Gijón and Barcelona (Spain), represent the idea of city-museum, city-facility, and, potentially, educational city, founded in the city as a construction of urbanity. Both are educational cities, and have generated heritage actions from obsolete industrial environments, introducing artworks, public sculpture, urban design furniture and unique buildings to transform and improve important cultural and social public places. A process of natural heritage education has been carried out at Barcelona, where the symbolism and value of art has been understood as another modern view into the cosmopolitan profile of the city. Gijón required a more direct and education-specific museum intervention, teaching its citizens to discover the 
true value of the historical and artistic heritage of their streets. An urban symbolism which acts as identitarian project has been created, transmitting cultural identity in both cases.

\section{ÍNDICE}

Keywords: museum, urbanity, identity

Palabras claves: patrimonio, urbanidad, identidad, museo

\section{AUTORES}

\section{ROSER CALAF}

Es profesora titular en la Universidad de Oviedo, y desde el año 2011 tiene concedida la Cátedra. Desde su línea de investigación sobre educación patrimonial ha desarrollado varios proyectos con financiación pública y privada (2001-2012). Sobre esta temática ha dirigido cinco tesis doctorales entre 2003 y 2010. Ha publicado Didáctica del Patrimonio: Epistemología, Metodología y Estudio de Casos (Trea, 2009) que es la consecuencia de su estancia de investigación en la Universidad de Laval (master de Museología), en Canadá. rcalaf@uniovi.es

\section{SUÉ GUTIÉRREZ}

Licenciada en Pedagogía y master en Intervención e Investigación Socioeducativa. Tiene experiencia como educadora social e infantil. Viene desarrollando su proyecto de tesis doctoral Valoración Didáctica de los Programas Educativos de los Museos de Patrimonio Artístico de Gijón desde el año 2012. Actualmente becaria de investigación del programa Severo Ochoa de Asturias. suegberciano@gmail.com 